\title{
Assessing Market-Sold Remedies in Lomé (Togo) for Hygienic Quality
}

\author{
Comlan de Souza, Yaovi Ameyapoh, Simplice D. Karou, Kokou T. Anani, \\ Madje L. Kpodar, and Mensavi Gbeassor \\ Centre de Recherche et de Formation sur les Plantes Médicinales (CEFOPLAM), ESTBA, Université de Lomé, Lomé BP 1515, Togo \\ Correspondence should be addressed to Simplice D. Karou, simplicekarou@hotmail.com
}

Received 25 May 2010; Revised 7 July 2010; Accepted 28 July 2010

Academic Editor: Yu Hong Wei

Copyright $\odot 2011$ Comlan de Souza et al. This is an open access article distributed under the Creative Commons Attribution License, which permits unrestricted use, distribution, and reproduction in any medium, provided the original work is properly cited.

\begin{abstract}
Traditional concoctions sold in marketplaces are always assumed to be safe and efficient; however, they can be potentially toxic because of poor hygienic practices in plant processing or storage. The present study aimed to assess for the microbial quality of market-sold vegetable drugs in Lomé. Thus, a total of 209 plant remedies were collected in marketplaces and analysed for the presence of total aerobic bacteria, total coliforms, thermotolerant coliforms, Staphylococcus aureus, sulphite reducing bacteria, and yeast and moulds according to the French Association of Normalisation (AFNOR) guidelines. The results revealed that all formulations were contaminated by several microorganisms, excepted alcohol-based mixtures. According to AFNOR limits nonconform drugs were according to total aerobic bacteria (86.96\% powders, $81.82 \%$ capsules, $66.67 \%$ tisanes, and $42.11 \%$ decoctions); to total coliforms $(9.10 \%$ capsules, $8.70 \%$ powders and $1.75 \%$ decoction); to yeasts and moulds $(77.78 \%$ ointments, $40 \%$ calcined powders, $36.36 \%$ capsules, and $23.91 \%$ powders). The microbiological analysis revealed that the majority of contaminating bacteria were gram positive catalase positive and oxidase positive bacilli. Quality control studies on market-sold remedies are currently needed to evaluate the microbial risk in consuming these products and they may allow the standardisation of plant processing and storage.
\end{abstract}

\section{Introduction}

Plants have formed the basis of traditional medicine (TM) that was used thousands years ago by humans. Until today plant-based medicine continues to play a key role in healthcare systems in many regions worldwide, principally in Africa where modern drugs are not affordable. Indeed, it has been estimated to $80 \%$ the percentage of people who only rely on TM for their primarily health care in Africa $[1,2]$. Following leads supplied with traditional healers (TH), many plants have been screened in laboratories for biological activities. The majority of these studies conducted in vitro or on animal models often showed scientific rational behind plant usage with sometimes isolation of single pure compounds as active principle [3-5]. However, theses studies are focussed on plant extracts prepared by scientists after collecting plant materials them self. The extractions are made with organic solvents such as chloroform, methanol, or ethanol; sometimes they make decoctions in accordance with traditional practices [6-9]. Very few works have been conducted on vegetable drugs directly provided by $\mathrm{TH}$, since the manufacturing of labelled and packaged herbal concoctions with claims to cure diseases is still new in Africa. The recipes and preparations are of TM origin while the packaging and presentations are western; of course they still lack western safety and quality controls $[10,11]$.

Working on these drugs must be a new challenge for many reasons. Using plants for medicinal purposes is a question of tradition and culture in Africa; thus collecting, processing, and applying plants or plant-based medication has been handed down from generation to generation. Traditional medicines with medicinal plants as their most important components are sold in market places or prescribed by $\mathrm{TH}$ in their homes $[12,13]$. The physical conditions and infrastructure in these markets are generally poor, with most plant material displayed in the open. Under these 
conditions, the material is exposed to microbial and insect attack as well as the effects of light, gases, and temperature. Often, these informal markets are situated close to both pedestrian and motor vehicle traffic, which places plant material in contact with various kinds of pollution [14]. The main problem with these drugs is their hygienic quality in three key regards: healers often collect plant material around or in bushes near habitations and prepare drugs without any preliminary treatment to eliminate indigenous microbes sometimes, plant processing is carried out in their homes in nonadequate hygienic conditions, and prepared drugs are stored in inappropriate conditions. Overall, the final product proposed to the patients is sometimes of poor hygienic quality [15].

The purpose of the present study was then to access for the microbial quality of vegetable drugs sold in marketplaces in Lomé town (Togo).

\section{Material and Methods}

2.1. Samples Collection. Drug samples analysed in the present study were collected from vegetable drug's sellers in marketplaces in Lomé town or around Lomé (Togo) from March to June 2006. Afterwards, enquiries were made with available drugs providers by oral questioning to access for plant processing in particular plant materials collections, diagram of drug preparations, and therapeutic indication of drugs if not available on the packages.

2.2. Cell Enumeration. All media used in this study were purchased from BioRad (France). For each sample, $10 \mathrm{~g}$ (for solid sample) or $10 \mathrm{~mL}$ (for liquid sample) were mixed with $90 \mathrm{~mL}$ trypton-salt water $(0.85 \% \mathrm{w} / \mathrm{v})$ and stored at ambient temperature for $45 \mathrm{~min}$. Afterwards, tenfold serial dilutions were made for each suspension and $1 \mathrm{~mL}$ diluted suspension was used to inoculate specific culture media for microbial isolation and enumeration as recommended by the French Association of Normalisation [16]. The total number of microorganisms expressed as Colony Forming Unit (cfu) per gram or per $\mathrm{mL}$ of sample was determined by standard plate count. The following microorganisms were enumerated under the following conditions.

(i) Total aerobic bacteria with Plate Count Agar (PCA) after 24 hours incubation at $30^{\circ} \mathrm{C}$.

(ii) Total coliforms and thermotolerant coliforms on Violet Red Bile Lactose (VRBL) after 24 hours incubation at 30 and $44^{\circ} \mathrm{C}$, respectively.

(iii) Staphylococcus aureus by counting chapman coagulase positive colonies after 24 hours incubation at $37^{\circ} \mathrm{C}$.

(iv) Sulphite Reducing Bacteria (SRB) by Most Probably Number (MPN) with tryptone-sulfite neomycin broth after 20 hours incubation at $44^{\circ} \mathrm{C}$.

(v) Yeast and moulds with Sabouraud-Cloranfenicol after 3 to 5 days incubation at $30^{\circ} \mathrm{C}$.

Microbial quality of drugs was assayed using the critical limits of French Association of Normalisation (AFNOR).

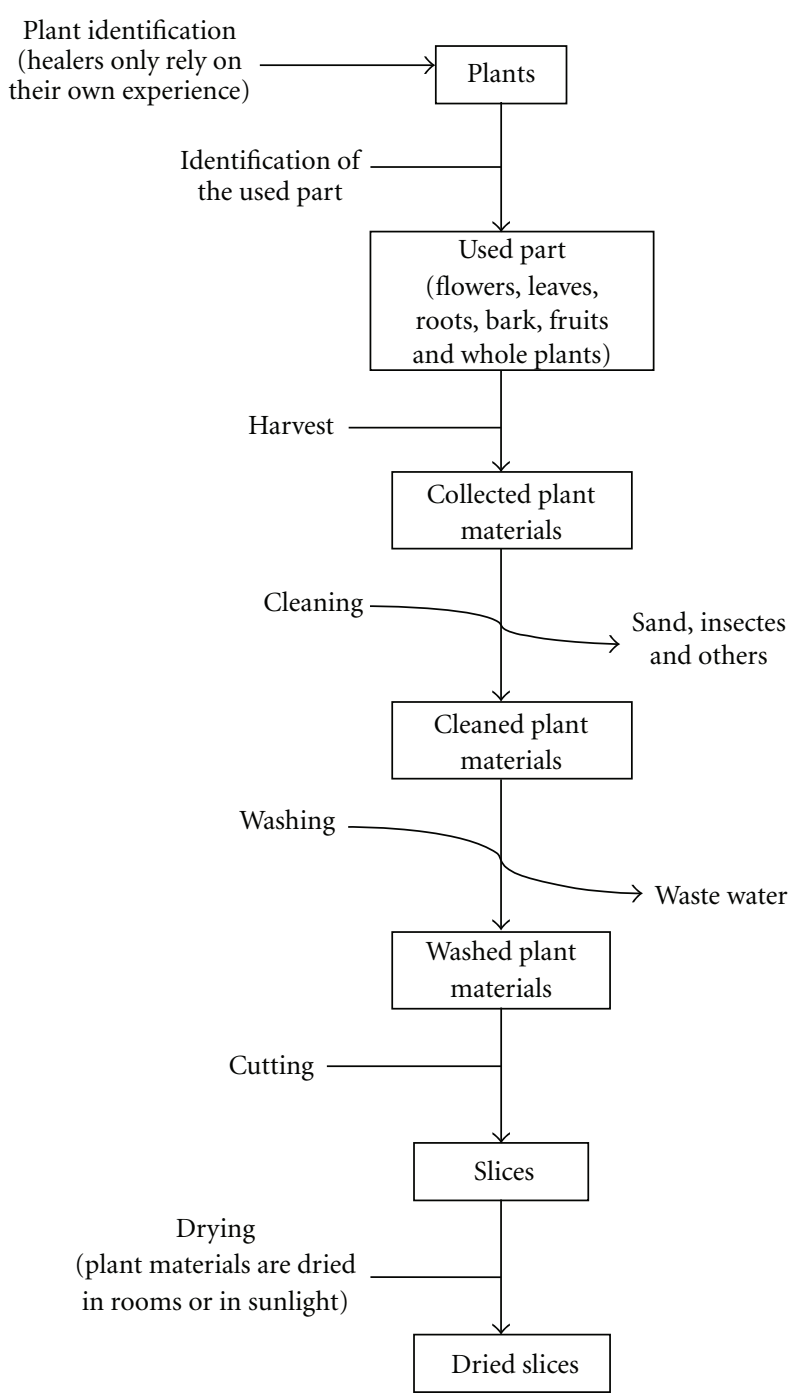

FIgURE 1: Diagram of plant material processing.

Catalase test was performed by adding hydrogen peroxide on a single colony. The presence of catalase was revealed by the formation of gas bubbles. Oxidase tests were performed using available commercial oxidase disks purchased from Bio Rad (France).

\section{Results}

3.1. Formulations and Therapeutic Indications. A total of 209 products were collected in marketplaces in Lomé town and in markets around the town. The drugs were presented in several formulations including decoctions, powders, capsules, ointments, soaps, alcohol-based mixtures (ABM), honey-based mixtures (HBM), calcined powders, and tisanes. Overall, decoctions formulations were most represented followed by powders and ointments (Table 1). Drugs were packed in bottles or in plastic sachets. Original packages with printed therapeutic indications and expiration dates accounted for $15 \%$ (31/209) of drugs. The others (85\%) were in recovered packages with therapeutic indications or 
TABLE 1: Formulations of market-sold remedies in Lomé.

\begin{tabular}{lc}
\hline Formulations & Percentages \\
\hline Decoctions & 27.27 \\
Powders & 22.01 \\
Ointment & 16.75 \\
Alcohol-based mixtures & 7.66 \\
Soaps & 7.66 \\
Capsules & 5.26 \\
Calcined powders & 4.79 \\
Tisanes & 4.79 \\
Honey-based mixtures & 4.30 \\
\hline Total number & 209 \\
\hline
\end{tabular}

without any information. In this case, therapeutic indications were orally provided by the seller. Another concern with theses remedies was that, the ingredients and their relative quantities were not listed on the product label. This was always kept as a secret for the TH.

Drugs were assumed to cure many diseases as indicated in Table 2. According to the table, microbial infections, sexual weakness, dermatitis, hypertension, and malaria were the most cited.

3.2. Plant Materials Processing. Enquiries with drug providers allowed accessing for the general procedure in drug preparation (Figure 1). Globally, plants materials were collected around habitations or in bushes and the healers only relied on their own experience in plant identification. Collected samples were processed in 5 steps including the cleaning and the washing, the cutting of the plant materials into small slices and the drying of the slices. Afterwards the treatment may differ according to the $\mathrm{TH}$ and the formulation of the product. The dried slices could be directly used as tisane, but for the other formulations the dried slices were ground in a mortar prior further processing.

(i) Powders and capsules: the ground plant materials are mixed with other substances of mineral or animal origin and the mixture can then be manually or semimanually packed in capsules or directly packed in bottles or in sachet and ready for use.

(ii) Calcined powders: the slices are calcined in a pot until darkness. The calcine is cooled with water and ground in a mortar. For use, many of theses powders are often dissolved in "sodabi," local liquor distilled from palm wine.

(iii) Honey-based mixture: this is prepared by adding the vegetable powder directly on the honey.

(iv) Soaps are prepared with vegetable or animal oil. The oil is boiled with vegetable powder until complete homogenisation of the mixture. The mixture is then filtered and mixed with sodium hydroxide or potassium hydroxide and boiled before cooling at room temperature in their packages.

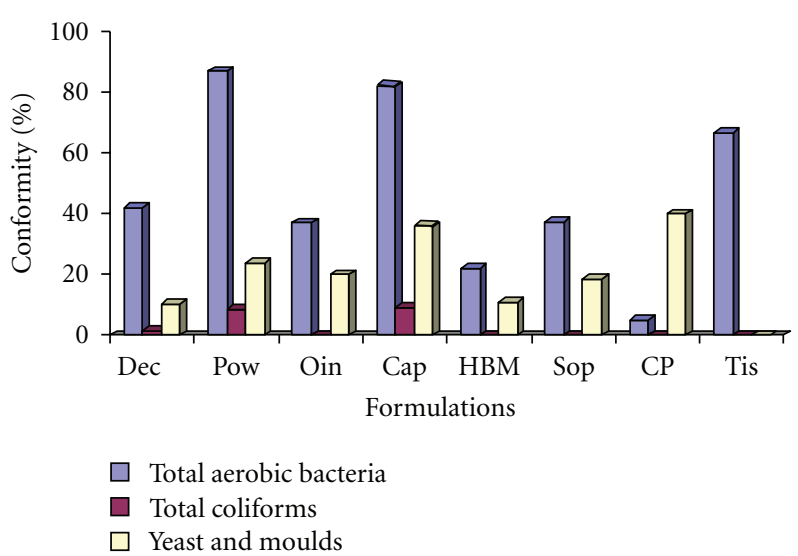

FIgure 2: Microbial contamination of market-sold remedies. Dec: Decoctions, Pow: Powders, Oin: Ointments, ABM: Alcohol-Based Mixtures, Cap: Capsules, Soa: Soaps, CP: Calcined powders, HBM: Honey-Based Mixtures, Tis: Tisanes.

(v) Ointments: the ground plant materials are mixed with melted shea butter or Vaseline colorant or essential oil can be added to the mixture and the product can be distributed in packages or stored.

(vi) Decoctions: the dried slices from single plant or plant mixture are boiled together with other products of animal origin or minerals. The boiling may take 1 to 12 hours according to $\mathrm{TH}$ or to products. After cooling in air to ambient temperature the product is packed in bottles or stored in drums.

(vii) ABM: local liquor distilled from palm wine and often called "sodadi" is added to the dried slices in bottles the mixture is allowed to stay for 15 to 30 days before use.

Microbial quality was assayed for all the 209 collected drugs. The following microorganisms were enumerated: total aerobic bacteria, total coliforms and thermotolerant coliforms, S. aureus, SRB, yeast, and moulds. According to our results, neither $S$. aureus nor BSR were found in the analysed products. For the other microorganisms, excepted $\mathrm{AMB}$, all the formulations were contaminated. The drugs were much contaminated by total aerobic microorganisms. Gram staining, catalase, and oxidase tests made on these microorganisms revealed that they were essentially gram positive, catalase positive, and oxidase bacilli. Total coliforms were found to occur in decoctions, powders, and capsules. Moulds and yeasts occurred in all formulations excepted tisanes and ABM. In accordance with the ARNOR limits, only $\mathrm{ABM}$ was conform according to all enumerated microorganisms. The conformity of the other drugs varied according to microorganisms. Figure 2 displays the percentages of nonconform drugs as a function of microorganisms. The majority of nonconform drugs were according to total aerobic bacteria: $86.96 \%$ powders, $81.82 \%$ capsules, $66.67 \%$ tisanes, and $42.11 \%$ decoctions. Yeast and moulds were the second agent of nonconformity of the products indeed, $40 \%$ 
TABLE 2: Therapeutic indications of market-sold remedies in Lomé.

\begin{tabular}{|c|c|c|c|c|c|c|c|c|c|c|}
\hline & Dec & Pow & Soa & $\mathrm{ABM}$ & Cap & Soa & HBM & $\mathrm{CP}$ & Tis & Total \\
\hline Malaria & 8 & 8 & - & - & - & - & 1 & - & 6 & 15 \\
\hline Microbial infections & 11 & 5 & 8 & 11 & 1 & - & - & 5 & 3 & 44 \\
\hline Dermatitis & 1 & - & 6 & - & - & 12 & - & - & - & 19 \\
\hline Haemorrhoids & 3 & 3 & - & - & - & - & - & - & - & 6 \\
\hline Sexual weaknesses & 12 & 15 & - & - & 5 & - & 4 & - & - & 36 \\
\hline Anaemia & 4 & - & - & - & - & - & 4 & - & - & 8 \\
\hline Hypertension & 7 & 5 & - & 5 & - & - & - & - & - & 17 \\
\hline Diabetes & 2 & 1 & - & - & - & - & - & - & - & 3 \\
\hline Intestinal parasites & 13 & - & - & - & - & - & - & 1 & - & 14 \\
\hline Candidiasis & - & 1 & 3 & - & - & - & 4 & - & - & 8 \\
\hline Hepatitis & - & 4 & - & 2 & - & - & - & - & - & 6 \\
\hline Sickles cell & - & - & - & - & 1 & - & - & - & - & 1 \\
\hline Dracunculosis & - & - & 5 & - & - & - & - & - & - & 5 \\
\hline
\end{tabular}

Dec: Decoctions, Pow: Powders, Oin: Ointments, ABM: Alcohol-based mixtures, Cap: Capsules, Soa: Soaps, CP: Calcinated Powders, HBM: Honey-based mixture, Tis: Tisanes, Hyp: Hypertension.

calcined powders, $36.36 \%$ capsules, and $23.91 \%$ powders were not conform according to these germs.

\section{Discussion}

The present study aimed to assess for the microbial quality of several vegetable drugs sold in Lomé town in order to evaluate the microbial risk in consuming these products. As many other countries in Africa, Togolese government recognises the importance of TM as a key provider of primary healthcare and is promoting the integration of traditional healing into the official health care system. However, treatment with traditional remedies may expose the patients to three major risks: the inefficacy of the remedy to cure the disease, the poisoning by toxic compound occurring in plant materials, and the poisoning by microbial toxins, or microorganisms occurring in poor hygienic quality remedies [17]. Nowadays, much effort is being made by scientists in solving the two first problems through biological screenings of plant extracts for biological activities in vitro or on animal models $[18,19]$. The main problem remains the poisoning by contaminating microorganisms or their toxins in plant products.

Contamination by microbial pathogen may occur in plant processing or during the storage [15]. The results of the present study revealed that the traditional remedies sold in Lomé marketplaces are contaminated by microbial pathogens; however, S. aureus and SRB were not detected in the drugs. The interest in detecting these two microorganisms is that $S$. aureus is the leading species of the genus Staphylococcus implicated in food poisoning infection. $\mathrm{SRB}$ are a group anaerobic sporulating bacteria including Clostridium, their spores resist after heat treatment and may cause damages after contaminated product consumption. Excepted ABM, contamination by total aerobic bacteria occurred for all formulations including decoctions which were also contaminated by total coliforms indicating faecal origin contamination. Since decoctions passed by a boiling step, their contamination occurred after the processing. In fact, some TH often prepare their drug in poor environmental conditions and store their drugs in nonsterile bottles as we remarked in our enquiries. Of course powders which do not pass by a heating step are more contaminated. Elimination of yeasts and mould from foods and other products remains difficult because they produce thermoresistant spore that survive heat treatment. Indeed our results indicated that all formulations were contaminated by yeast and mould excepted ABM and tisanes. The main risk with theses microorganisms is the fact that some strains can elaborate mycotoxins occasioning poisoning.

Despite microbial contamination of market-sold traditional remedies, expiration dates could also be pointed out. In our enquiries many healers did not mention expiration date of their products. The ones who provided it only relied on empirical observations. It is evident that the biological activity of plant extract is time-dependent, phenolic compounds are the main examples. They are vulnerable to polymerization through air oxidization. High polymerization results in insoluble complex that precipitate in solution. This oxidization may first affect the extractability of the phenolic compounds that is crucial in drug preparation; in this topic some authors suggested extracting the compounds directly on fresh material in order to enhance the yield [20]. Secondly, an important factor governing the activity of phenolic compounds is their polymerization size. Oxidized condensation of phenols may result in the toxification of microorganisms, while the adverse effects can be observed in some cases [21-23]. Storage and drying process may then affect the chemical composition of the material. It is useful to use fresh material rather than dried material but this is the form which is usually preferred by traditional healers [24]. In accordance with these observations relying only on empirical observations to estimate expiration date is not the 
adequate way. In addition, TH rely on empirical experience in the plant identification, there also remains a major risk of misidentification.

The lack of quality control and regulations on standardisation of natural products may result in varying concentrations of active compounds, consumption of contaminants such as microbes or their microbial toxins, heavy metals, and possible fatal side effects as a result of misidentification of plant material. In addition, convincing $\mathrm{TH}$ to reveal their ingredients as well as the recipes of their products as it is a guarded secret amongst them still remains a challenge.

\section{Acknowledgment}

The authors gratefully thank the traditional healers who accepted to answer to their questions.

\section{References}

[1] K. Hostettmann and A. Marston, "Twenty years of research into medicinal plants: results and perspectives," Phytochemistry Reviews, vol. 1, no. 3, pp. 275-285, 2002.

[2] WHO, "Traditional medicine," 2009, http://www.who.int/topics/traditional_medicine/en.

[3] J. R. Gómez Castellanos, J. M. Prieto, and M. Heinrich, "Red Lapacho (Tabebuia impetiginosa) — a global ethnopharmacological commodity?" Journal of Ethnopharmacology, vol. 121, no. 1, pp. 1-13, 2009.

[4] D. Karou, M. H. Dicko, S. Sanon, J. Simpore, and A. S. Traore, "Antimalarial activity of Sida acuta Burm. f. (Malvaceae) and Pterocarpus erinaceus Poir. (Fabaceae)," Journal of Ethnopharmacology, vol. 89, no. 2-3, pp. 291-294, 2003.

[5] D. Karou, A. Savadogo, A. Canini et al., "Antibacterial activity of alkaloids from Sida acuta," African Journal of Biotechnology, vol. 5, no. 2, pp. 195-200, 2006.

[6] E. F. Akomo, C. Zongo, S. D. Karou et al., "In vitro antiplasmodial and antibacterial activities of Canthium multiflorum Schum and Thonn (Rubiacea) extracts," Pakistan Journal of Biological Sciences, vol. 12, no. 12, pp. 919-923, 2009.

[7] D. Olila, J. Opuda-Asibo, and O. Odyek, "Bioassay-guided studies on the cytotoxic and in vitro trypanocidal activities of a sesquiterpene (Muzigadial) derived from a Ugandan medicinal plant (Warburgia ugandensis)," African Health Sciences, vol. 1, no. 1, pp. 12-15, 2001.

[8] S. D. Karou, W. M. C. Nadembega, D. P. Ilboudo et al., "Sida acuta Burm. f.: a medicinal plant with numerous potencies," African Journal of Biotechnology, vol. 6, no. 25, pp. 2953-2959, 2007.

[9] D. Karou, W. M. C. Nadembega, L. Ouattara, et al., "African ethnopharmacology and new drug discovery," Medicinal and Aromatic Plant Science and Biotechnology, vol. 1, no. 1, pp. 6169, 2007.

[10] J. Gertsch, "How scientific is the science in ethnopharmacology? Historical perspectives and epistemological problems," Journal of Ethnopharmacology, vol. 122, no. 2, pp. 177-183, 2009.

[11] A. R. Ndhlala, G. I. Stafford, J. F. Finnie, and J. Van Staden, "In vitro pharmacological effects of manufactured herbal concoctions used in KwaZulu-Natal South Africa," Journal of Ethnopharmacology, vol. 122, no. 1, pp. 117-122, 2009.

[12] H. T. von Maydell, Trees and Shrubs of the Sahel, Josef Margraf, Weikersheim, Germany, 1996.
[13] K. K. Ajibesin, B. A. Ekpo, D. N. Bala, E. E. Essien, and S. A. Adesanya, "Ethnobotanical survey of Akwa Ibom State of Nigeria," Journal of Ethnopharmacology, vol. 115, no. 3, pp. 387-408, 2008.

[14] M. Mander, The Marketing of Indigenous Medicinal Plants in South Africa: A Case Study in Kwazulu-Natal, Institute of Natural Resources, Pietermaritzburg, South Africa, 1997.

[15] A. M. Djikpo-Tchibozo, K. Anani, Y. Ameyapoh, et al., "Evaluation de la qualité hygiénique de six plantes médicinales et des phytomédicaments traditionnels," Pharm Med Trad Afr, vol. 11, pp. 83-92, 2001.

[16] AFNOR (Association Française de Normalisation), "Normes Agroalimentaires," 2009, http://www.afnor.org/secteurs/activite/agroalimentaire/normes/liste-des-norme.

[17] C. W. Fennell, K. L. Lindsey, L. J. McGaw et al., "Assessing African medicinal plants for efficacy and safety: pharmacological screening and toxicology," Journal of Ethnopharmacology, vol. 94, no. 2-3, pp. 205-217, 2004.

[18] C. N. Uchendu and T. Isek, "Antifertility activity of aqueous ethanolic leaf extract of Spondias mombin (Anacardiaceae) in rats," African Health Sciences, vol. 8, no. 3, pp. 163-167, 2008.

[19] J. W. Ogwal-Okeng, C. Obua, and W. W. Anokbonggo, "Acute toxicity effects of the methanolic extract of Fagara zanthoxyloides (Lam.) root-bark," African Health Sciences, vol. 3, no. 3, pp. 124-126, 2003.

[20] A. Scalbert, "Quantitative methods for the estimation tannins in plants tissues," in Plants Polyphenols: Synthesis, Properties, Significance, R. W. Hemingway and E. P. Laks, Eds., pp. 673692, Plenum Press, New York, NY, USA, 1992.

[21] A. Scalbert, "Antimicrobial properties of tannins," Phytochemistry, vol. 30, no. 12, pp. 3875-3883, 1991.

[22] J. A. Field and G. Lettinga, "Toxicity of tannic compounds to microorganisms," in Plant Polyphenols: Synthesis, Properties, Significance, R. W. Hemingway and E. P. Laks, Eds., pp. 673692, Plenum Press, New York, NY, USA, 2002.

[23] D. Karou, M. H. Dicko, J. Simpore, and A. S. Traore, "Antioxidant and antibacterial activities of polyphenols from ethnomedicinal plants of Burkina Faso," African Journal of Biotechnology, vol. 4, no. 8, pp. 823-828, 2005.

[24] G. I. Stafford, A. K. Jäger, and J. Van Staden, "Effect of storage on the chemical composition and biological activity of several popular South African medicinal plants," Journal of Ethnopharmacology, vol. 97, no. 1, pp. 107-115, 2005. 

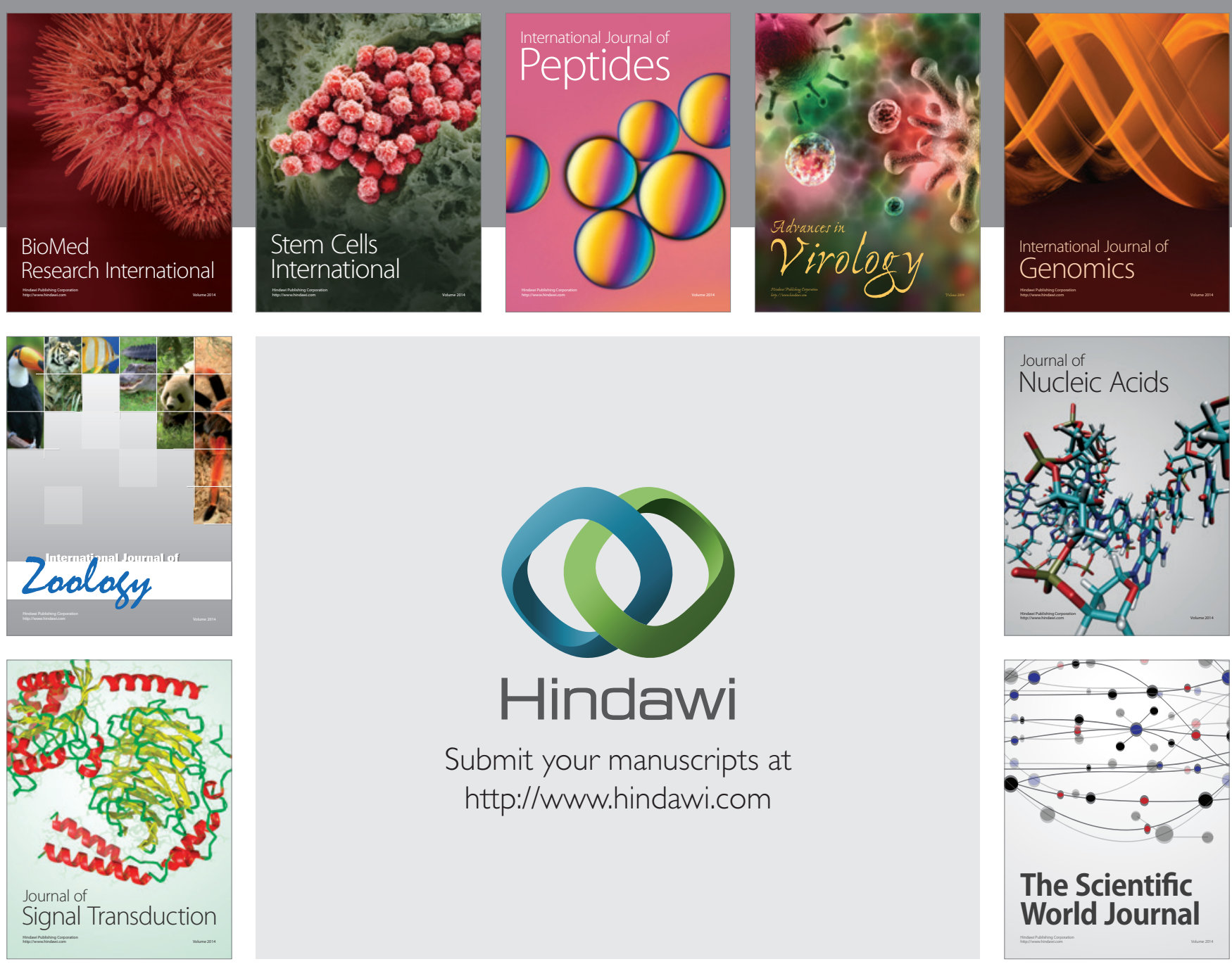

Submit your manuscripts at

http://www.hindawi.com
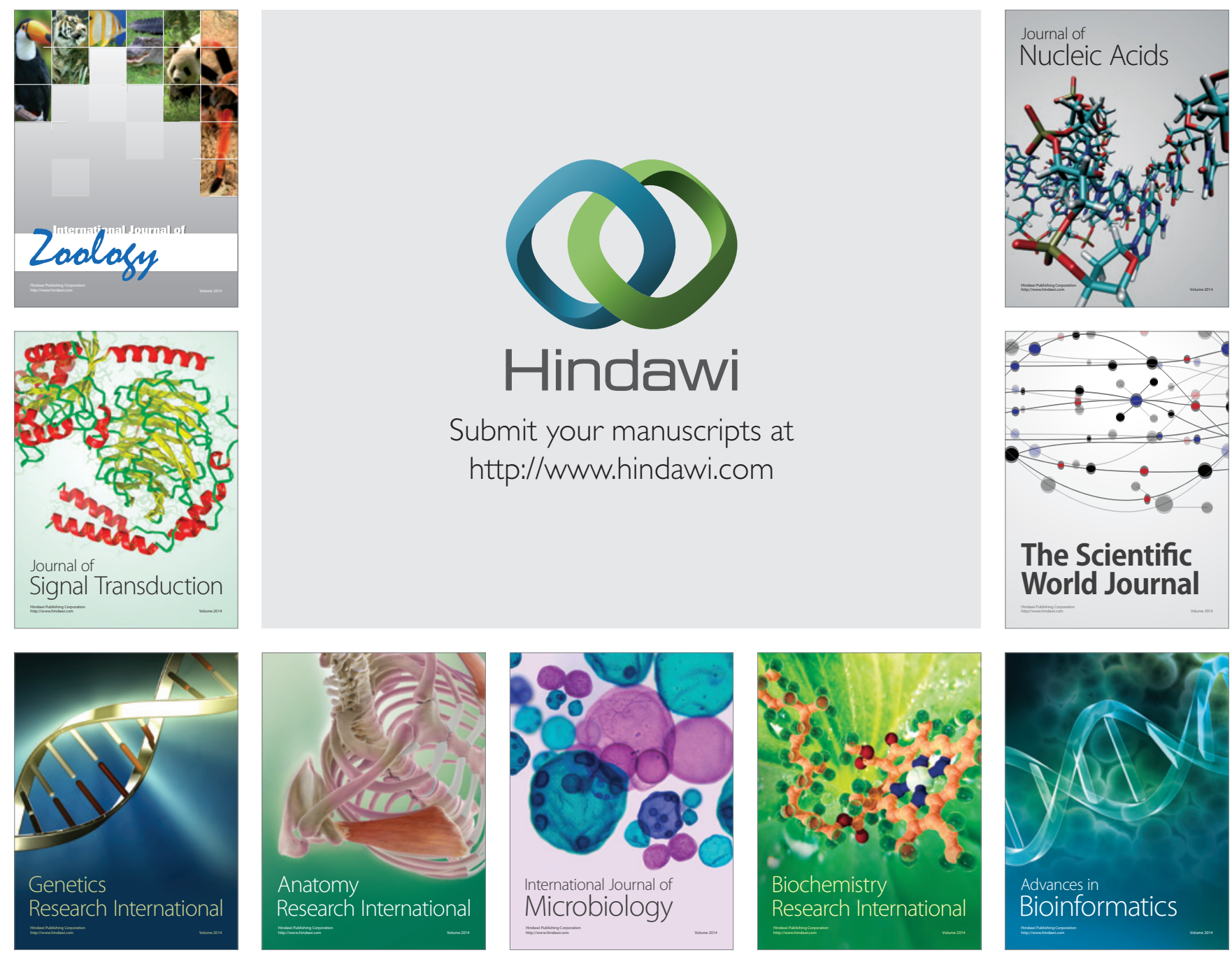

The Scientific World Journal
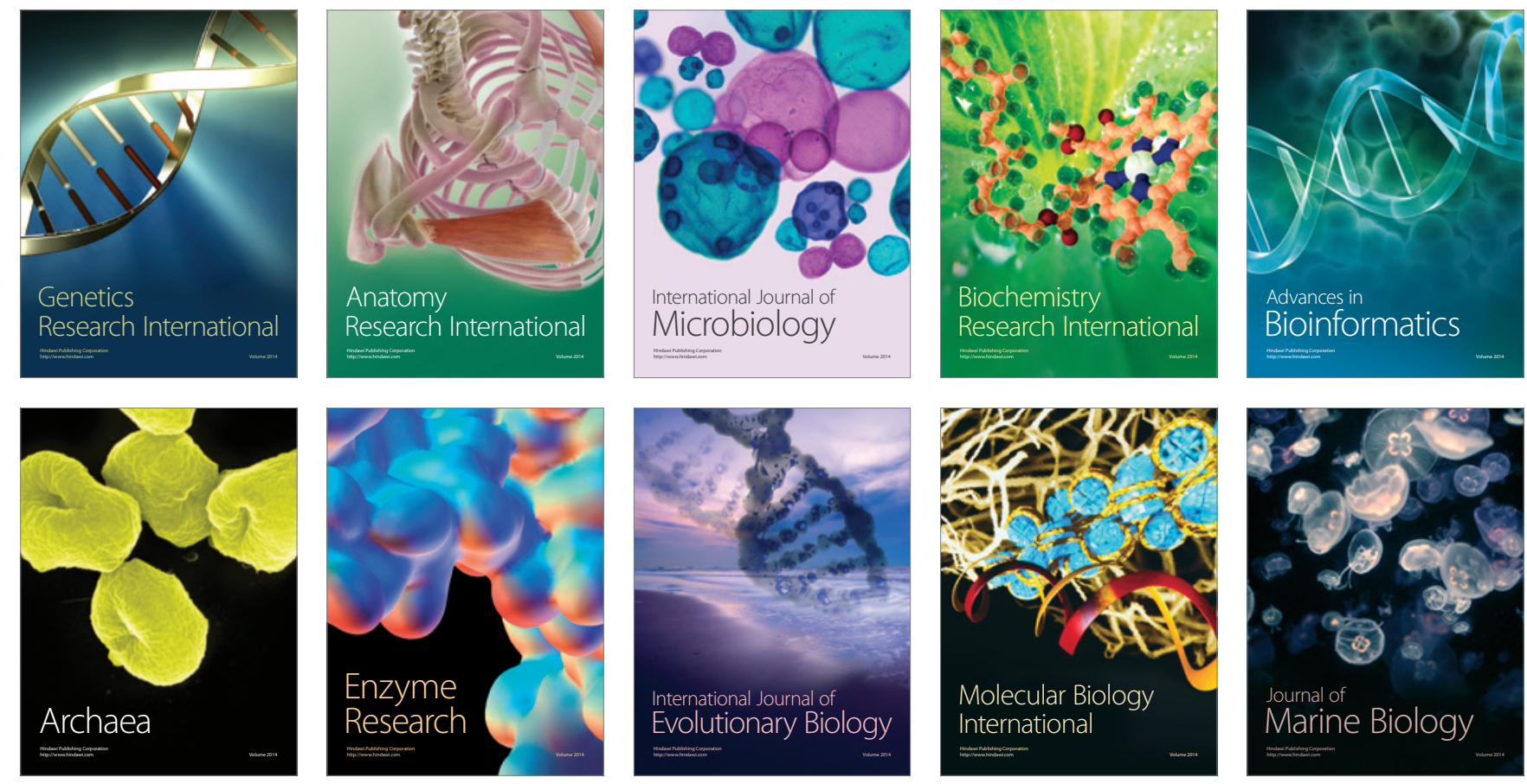